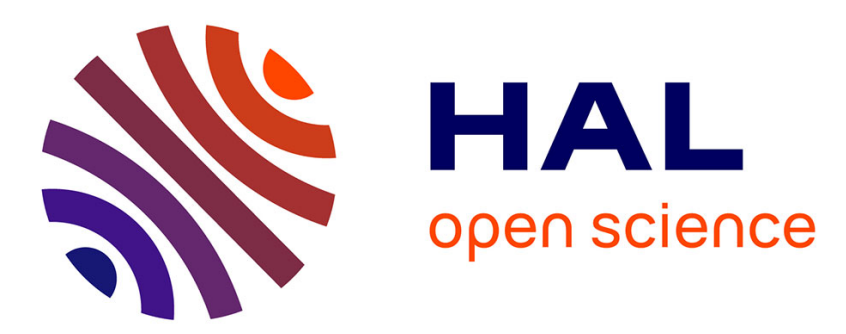

\title{
Investigation of Scaling Effects in Elastic-Plastic Ductile Fracture Using the Local Approach
}

\author{
J. Giovanola, S. Kirkpatrick, J. Crocker
}

\section{To cite this version:}

J. Giovanola, S. Kirkpatrick, J. Crocker. Investigation of Scaling Effects in Elastic-Plastic Ductile Fracture Using the Local Approach. Journal de Physique IV Proceedings, 1996, 06 (C6), pp.C6-513C6-520. 10.1051/.jp4:1996651 . jpa-00254484

\section{HAL Id: jpa-00254484 https://hal.science/jpa-00254484}

Submitted on 1 Jan 1996

HAL is a multi-disciplinary open access archive for the deposit and dissemination of scientific research documents, whether they are published or not. The documents may come from teaching and research institutions in France or abroad, or from public or private research centers.
L'archive ouverte pluridisciplinaire HAL, est destinée au dépôt et à la diffusion de documents scientifiques de niveau recherche, publiés ou non, émanant des établissements d'enseignement et de recherche français ou étrangers, des laboratoires publics ou privés. 


\title{
Investigation of Scaling Effects in Elastic-Plastic Ductile Fracture Using the Local Approach
}

\author{
J.H. Giovanola, S.W. Kirkpatrick and J.E. Crocker* \\ SRI International, Poulter Laboratory, 333 Ravenswood Avenue, Menlo Park, CA 94025-3493, U.S.A. \\ * University of Connecticut, Department of Materials Science, Storrs, CT, U.S.A.
}

\begin{abstract}
This paper investigates the ability of a simple ductile local fracture model to predict the fracture initiation conditions for geometrically similar specimens of different sizes containing either sharp cracks or biunt notches. The material considered is the high strength, low hardening HY 130 steel. We simulated fracture tests on fatigue-precracked compact tension specimens and three-point bend bars containing blunt notches, using the local fracture model to control crack initiation in the finite element analyses. We compared the results of the simulations with experimental results. The comparison indicates that the model qualitatively predicts the right scaling effects for cracked specimens when a characteristic material length is adequately introduced. However, the model failed to predict the fracture initiation conditions and the scaling behavior of notched specimens. The discrepancy arises because the actual micromechanism leading to fracture initiation at the notch (void growth in a band of localized shear) is different from the mechanism underlying the model (quasi-isotropic void growth). Therefore, new or improved models capable of handling ductile failure by void growth under predominantly shear deformation must be developed to predict ductile fracture initiation conditions and scaling laws for generalized loading and geometric configurations.
\end{abstract}

\section{INTRODUCTION}

The essence of fracture mechanics theories is to provide scaling rules, so that results of laboratory experiments on small specimens can be used to predict the fracture behavior of much larger structures. Local fracture approaches may allow the derivation of fracture scaling rules for much more general loading and geometric configurations than classical K- or J-based fracture mechanics approaches, which are limited to cases of fracture initiating at preexisting sharp cracks. Indeed, many safety, crashworthiness, or manufacturing problems require that failure of engineering parts made of initially unflawed material be considered.

We investigated the ability of a simple ductile local fracture model to analyze fracture for more general loading and geometric configurations and to establish the corresponding scaling laws. More specifically, we attempted to predict the fracture conditions for replica-scaled specimens, that is, geornetrically similar specimens of different sizes, containing either sharp cracks or blunt notches. The following key questions are addressed by this paper: (1) Can a simple local fracture model containing $a$ characteristic material length scale and implemented in a finite element code predict experimentally observed scaling effects in cracked specimens? (2) Can such a model also predict fracture conditions and the associated scaling effects for specimens with blunt notches? We consider the microdamage mode of ductile fracture by nucleation, growth, and coalescence of voids under macroscopic elasto-plastic or fully plastic conditions. We do not consider rate effects or statistical effects associated with the microstructural variations. The study focuses on a single material, HY-130 steel, a high strength, low hardening steel with yield strength of $940 \mathrm{MPa}$. Details of the study are presented in references 1 and 2 . Here, we only summarize the approach and the results. 


\section{APPROACH}

To evaluate the ability of ductile local fracture models to predict scaling effects, we selected a simple model and used it to simulate geometrically scaled cracked compact tension (CT) specimens and notched three-point-bend (N3PB) specimens loaded to fracture. We then compared the calculated normalized load-displacement curves, the conditions for fracture initiation, and the crack extension-displacement curves with corresponding experimental data. We complemented this comparison with fractographic observations to rationalize some of our observations.

\subsection{Simulations}

\subsubsection{Local Ductile Fracture Model}

The local ductile fracture model we used in our investigation was proposed by Mackenzie et al. [3] (see also Mudry [4]). It assumes that failure of a material location occurs when the damage within a surrounding characteristic volume $\mathrm{V}_{\text {MIC }}$ exceeds a critical value that is

$$
\mathrm{D}=\hat{\jmath} \frac{\mathrm{d} \varepsilon_{\mathrm{eq}}^{\mathrm{p}}}{\varepsilon_{\mathrm{c}}\left(\sigma^{*}\right)}=1 \quad \text { over } \mathrm{V}_{\mathrm{MIC}}=\left(\mathrm{R}_{\mathrm{MIC}}\right)^{3}
$$

where $D$ is the normalized damage parameter, $d \varepsilon_{\mathrm{eq}}^{\mathrm{p}}$ is an increment in equivalent plastic strain, and e $\left(\sigma^{*}\right)$ is the critical failure strain as a function of the stress triaxiality $\sigma^{*}$, defined as the ratio of the mean stress to the equivalent stress. This critical strain function can be determined by a series of notched tensile tests with specimens of varying notch radii. $V_{M I C}$ and $R_{M I C}$ are the volume and radius of the process zone, respectively. These constant microstructural parameters introduce nongeometric scaling effects. The fracture model is implemented in a version of the explicit finite element code DYNA3D [5], which contains a node release feature allowing the simulation of propagating cracks. The simple model of Equation (1) is equivalent to other ductile local fracture models such as the Beremin model [6] or the model proposed by Norris $e t$ al. [7].

We did not rigorously calibrate the local fracture model for this investigation. Rather, we used the experimentally measured failure strain versus stress triaxiality curve for HY 130 steel provided by Mackenzie et al. [3]. These data are only approximate because the authors obtained the triaxiality level in notched round bar specimens from the Bridgman analysis [8]. Further, we did not select the value of $R_{\text {MIC }}$ by a calibration procedure, but chose $\mathbf{R}_{\text {MIC }}$ somewhat arbitrarily to be $200 \mu \mathrm{m}$ on the basis of the experience of other authors for different, lower strength steels [4]. We obtained an estimate of the constitutive behavior at large strains for HY-130 steel by applying the Bridgman correction [8] to stress-strain data measured in a tensile test after necking.

In the finite element simulations of scaled fracture specimens, we used a single mesh for all specimen sizes of the same geometry so that the number of elements remained constant, and stress and strain gradients were always calculcated with the same accuracy. We introduced the absolute size of the specimens by way of the constant characteristic material length scale, or process zone size, $\mathbf{R}_{\mathrm{MIC}}$. To keep $\mathbf{R}_{\mathrm{MIC}}$ constant as the specimen size decreased, we increased the size of the process zone relative to the finite element mesh; that is we integrated damage over an increasing number of elements (see reference 2 for details). We kept the absolute value of $R_{\text {MIC }}$ the same $(200 \mu \mathrm{m})$ for both the CT and N3PB specimens. This approach for implementing the characteristic length scale differs from the commonly used method of making the element size equal to the length scale in the fracture region. We showed earlier that the latter practice can lead to erroneous effects of the mesh on the results of scaling studies [9].

\subsubsection{Simulation of Fracture Experiments}

We simulated CT and N3PB specimens of different sizes with the three-dimensional DYNA3D finite element code, using a single layer of eight-noded elements and assuming plane-strain conditions in the out-of-plane direction. Therefore, the simulations were essentially two-dimensional. Figure 1 shows the meshes used for all the simulations of the CT and N3PB specimens. The size of the simulated CT specimens differed by a factor of 4 and had the in-plane dimensions of standard ASTM 0.375T and 1.5T specimens [10]. The ratio of crack depth to specimen width was 0.7 to 0.71 . Similarly, the size of the simulated N3PB specimens differed by factors of 2 and 4 and had the in-plane dimensions of standard ASTM 0.5T, 1T, and 2T specimens 


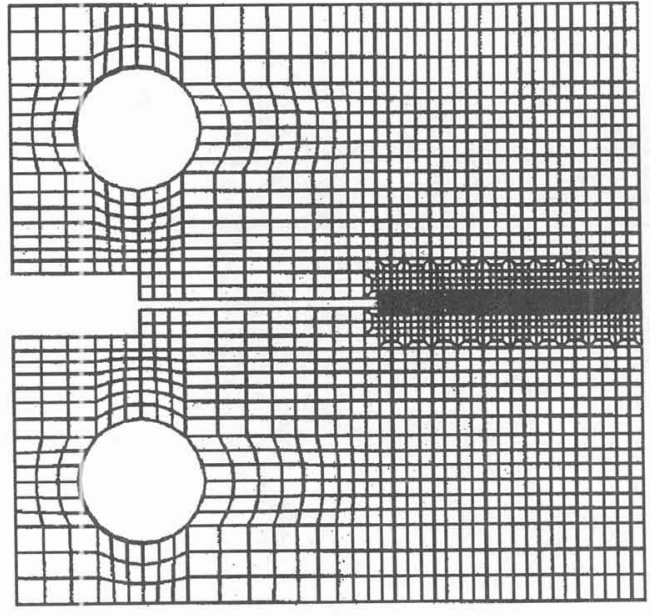

a) Overall view of the CT specimen mesh

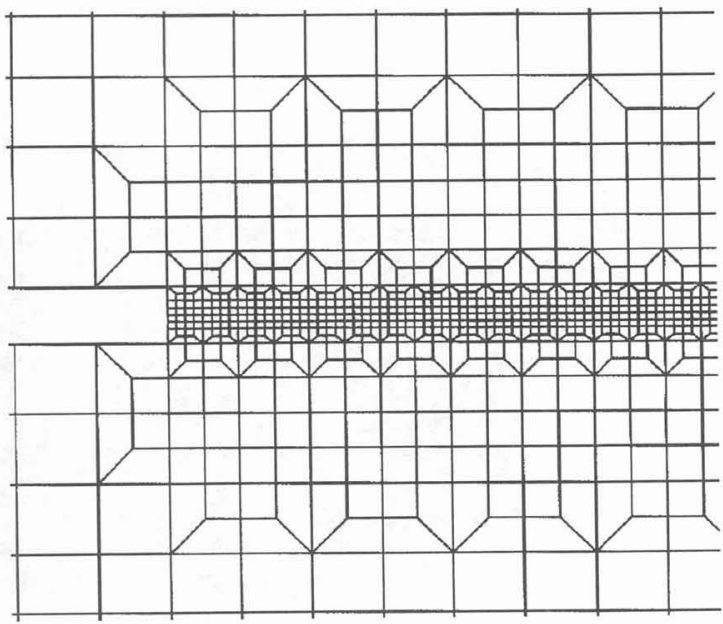

b) Detail of the mesh near the crack plane

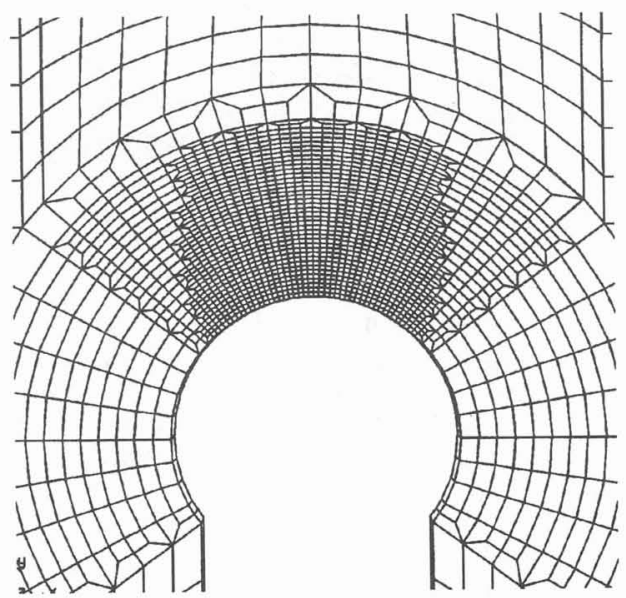

d) Detail of the mesh near the notch tip

c) Overall view of the blunt notch bend bar mesh

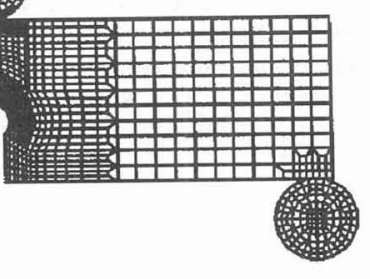

Figure 1. Finite element mesh for simulations of the fracture tests.

[10]. The N3PB specimens contained a straight-face notch terminated by a semicircular tip. The ratio of notch depth to specimen width was 0.5 , and the ratio of the radius of the notch root to specimen width was 0.125 . The three-point bending configuration involved a ratio of span between supports to specimen width of 8 .

\subsection{Fracture Experiments}

We obtained data for crack initiation and propagation tests on standard 1T and 4T 20\% side-grooved fatigue precracked CT specimens of HY 130 steel from another investigation [11]. The available data included the load versus load-point displacement curves as well as the crack extension versus load-point displacement curves. 


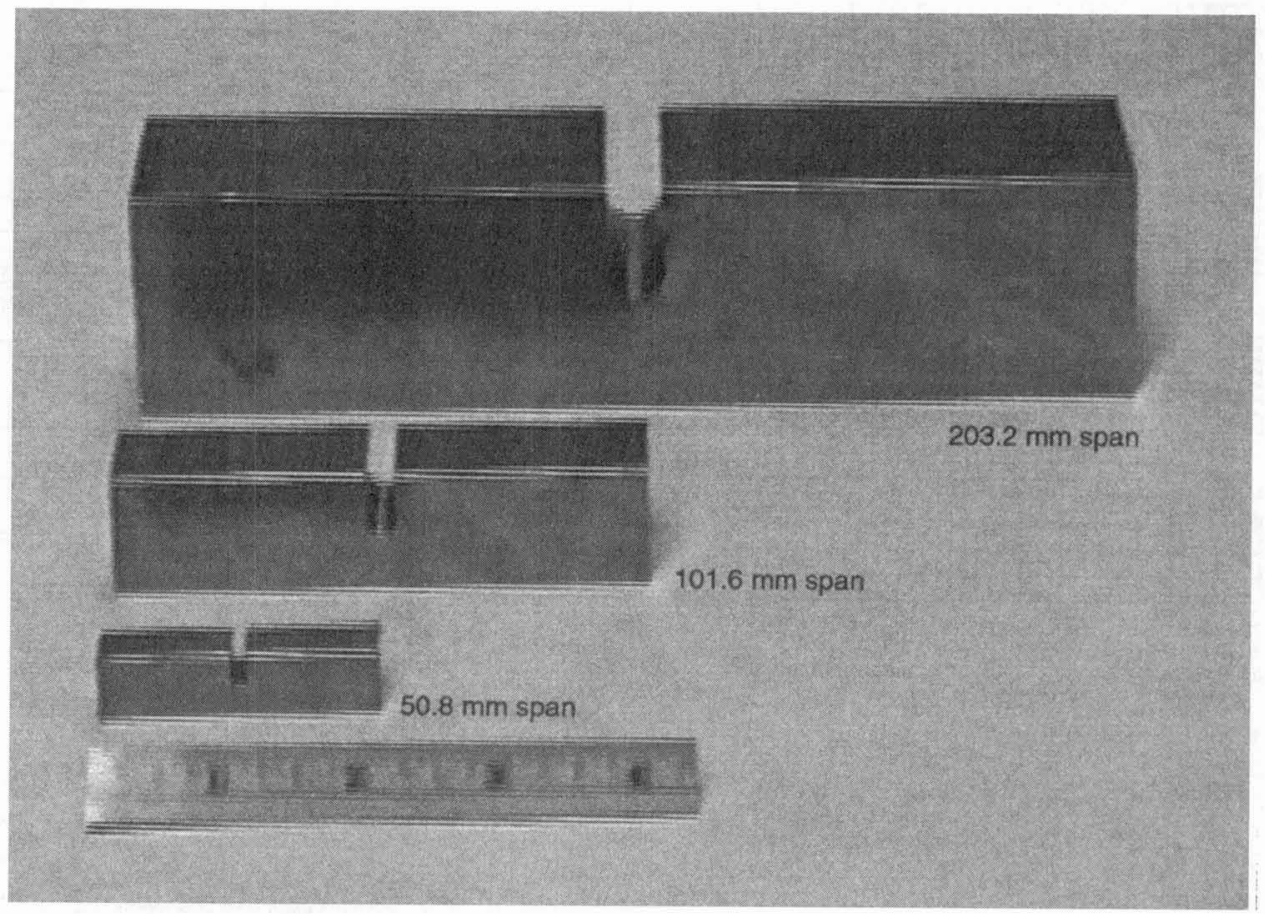

Figure 2. Scaled notched three-point-bend specimens.

We fabricated and tested N3PB specimens of the sizes specified in the previous section. Figure 2 shows a photograph of these geometrically scaled specimens. During the experiments, we measured load, load-point displacement, notch-mouth opening displacement, and acoustic emission, and we monitored and recorded the deformation and cracking at the notch root with a microscope and a video camera. This instrumentation allowed us to establish with precision the point at which fracture initiated in the notched specimens.

\section{RESULTS}

\subsection{RESULTS OF SIMULATIONS}

\subsubsection{Scaled Compact Tension Specimens}

Figure 3 shows the simulated normalized load and crack versus load-line displacement curves for a $0.375 \mathrm{~T}$ and a $1.5 \mathrm{~T}$ CT specimen. We normalized the load by dividing it by the limit load (given in Reference 12) and by dividing the displacement and crack extension by the specimen width. The fracture simulations based on the model of Equation (1) and its finite element implementation indicate that a factor of 4 in specimen size leads to significant differences in the peak load and the displacement at the point of crack initiation. As is well known from classical fracture mechanics, the small specimen is more fracture-resistant than the large one.

\subsubsection{Scaled Notched Three-Point-Bend Specimens}

Figure 4 shows the simulated normalized load versus load-point displacement curves for the $0.5 \mathrm{~T}, 1 \mathrm{~T}$, and 2T N3PB specimens. Again, we normalized the load by the limit load [12] and the displacement and crack 


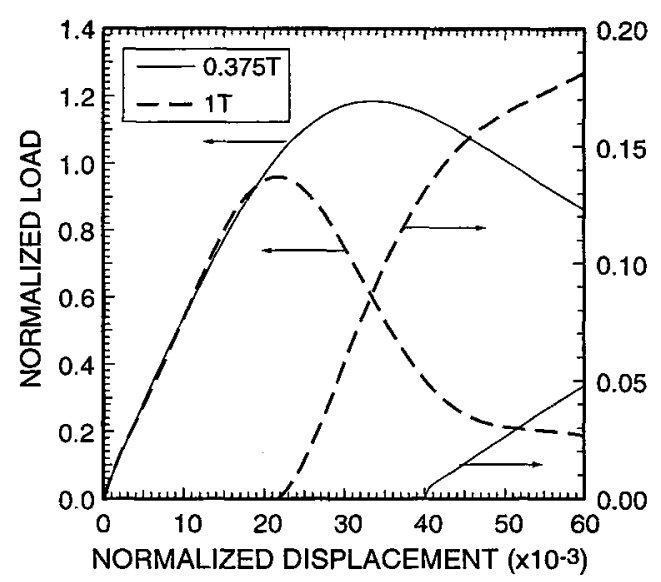

Figure 3. Simulated fracture behavior of $0.375 \mathrm{~T}$ and $1 \mathrm{~T}$ compact tension specimens.

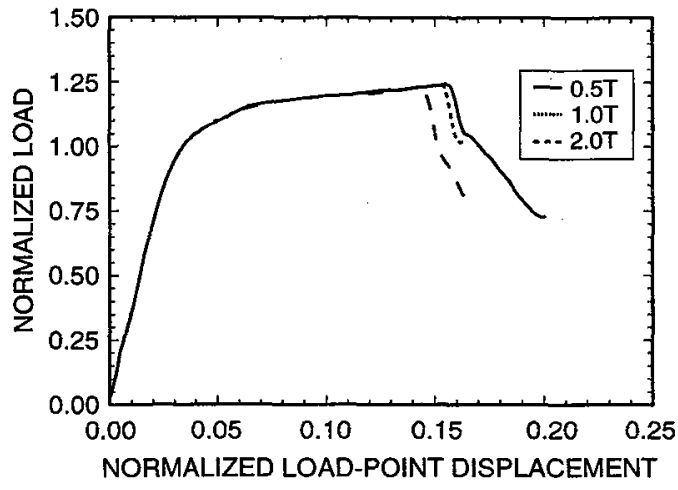

Figure 4. Simulated fracture behavior of $0.5 \mathrm{~T}, 1 \mathrm{~T}$ and $2 \mathrm{~T}$ three-point-bend specimens.

extension by the specimen width. As can be expected from continuum mechanics considerations, the load displacement curves up to the point of fracture initiation are indistinguishable. Fracture initiates in the three specimen sizes at only slightly different normalized displacements, so that in contrast to initiation at sharp cracks, the simulations predict little or no scaling effect for initiation at blunt notches. As discussed in reference 2 , this result can be obtained from simple consideration of the gradients in field quantities ahead of the notch together with the fracture criterion of Equation (1). However, we will see below that it is not borne out by the experimental data. The simulations also predict crack initiation and propagation on the specimen symrnetry plane along the notch axis.

\subsection{RESULTS OF EXPERIMENTS}

\subsubsection{Scaled Compact Tension Specimens}

Figure 5 shows the normalized experimental load and crack extension versus load-line displacement curves for $20 \%$ side-grooved $1 \mathrm{~T}$ and $4 \mathrm{~T}$ CT specimens. The normalization procedure was the same as that applied

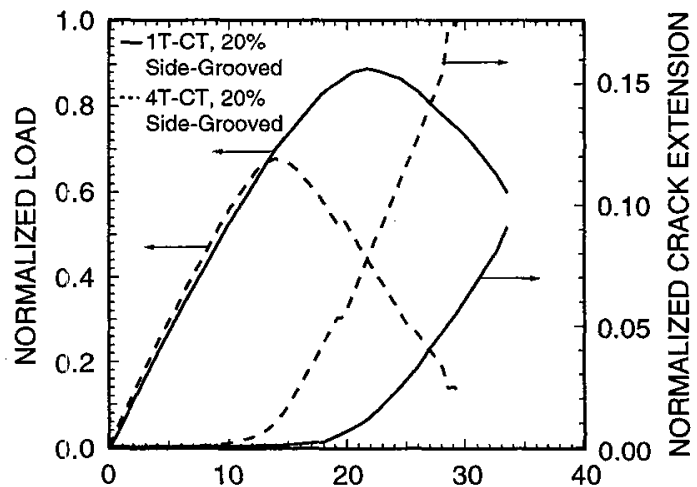

NORMALIZED LOAD LINE DISPLACEMENT (x10-3) Courtesy of Dr. R. Link, NSWC Annapolis

Figure 5. Experimentally measured fracture behavior of $1 \mathrm{~T}$ and 4.T 20\% side-grooved compact tension specimens.



Figure 6. Experimentally measured fracture behavior of $0.5 \mathrm{~T}, 1 \mathrm{~T}$ and $2 \mathrm{~T}$ notched three-point-bend specimens. 
to the numerical results. The scaling effect indicated by Figure 5 is similar to that indicated in Figure 3 for the same scaling factor (but for different absolute specimen sizes).

\subsubsection{Scaled Notched Three-Point-Bend Specimens}

Figure 6 shows the normalized experimental load versus load-point displacement curve for the $0.5 \mathrm{~T}, 1 \mathrm{~T}$, and 2T N3PB specimens. The normalization procedure was the same as that applied to the numerical results. The arrows along the curves of Figure 6 indicate the average displacement at fracture initiation, and the bar indicates the extreme values. Multiple experiments for each specimen size demonstrate that the results are

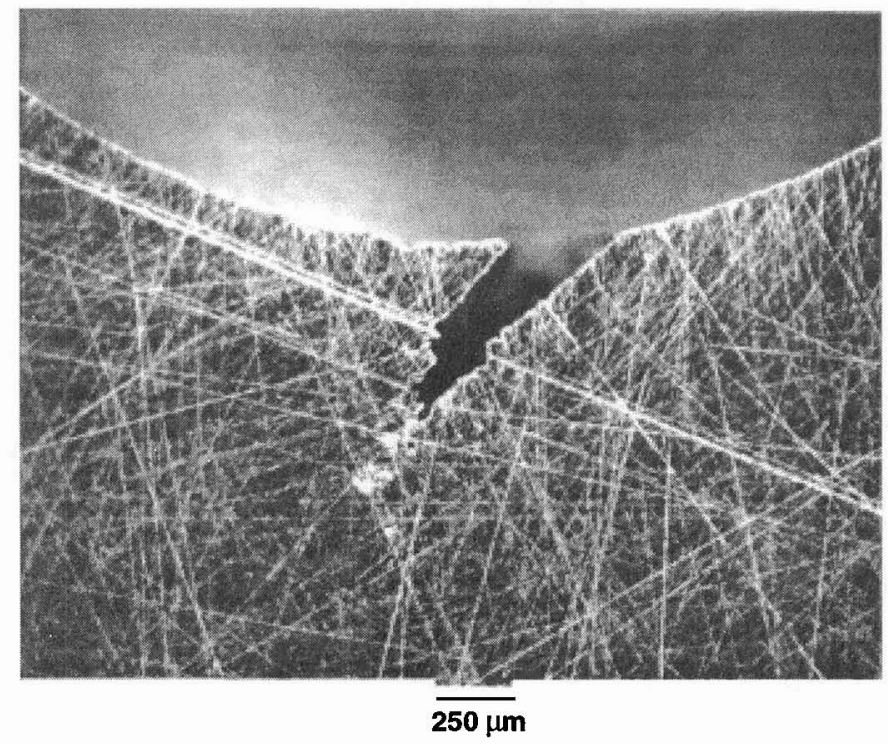

Figure 7. Cross section through the mid-thickness of a $0.375 \mathrm{~T}$ notched three-point-bend specimen showing inclined shear crack.

repeatable and that the difference observed for different specimens sizes cannot be attributed to experimental scatter. Therefore, the experimental results show that, contrary to the predictions based on the ductile local fracture model, the initiation of fracture does not follow geometrical scaling and that larger specimens with blunt notches fracture at significantly smaller levels of deformation than small specimens.

Figure 7 shows the profile of a just-initiated crack as observed in a metallographic cross section normal to the thickness direction at midthickness of a small $0.5 \mathrm{~T}$ specimen. Note that the crack is inclined with respect to the midplane of the specimen (symmetry plane defined by the thickness and width directions), and that crack initiation occurred under conditions of localized shear deformation. Again, this observation of the crack path differs from the simulation predictions. The microscopic mode of fracture remained, however, nucleation and growth of microvoids under mixed shear and tensile loading, although no isolated voids are found outside the crack path. We made similar fractographic observations in all specimen sizes.

\section{DISCUSSION AND CONCLUSIONS}

The modeling work presented here has several limitations that we need to consider when discussing the results. First, as pointed out earlier, the ductile fracture model was only cursorily calibrated. Second, we performed what essentially amounts to two-dimensional plane strain simulations of three-dimensional experiments. Three-dimensional effects may be important in the N3PB experiments, where we observed 
significant deformations in the thickness direction. Third, in analyzing scaling effects for cracked specimens, we are comparing specimens of different size ranges in the numerical simulations and in the experiments.

Some of the analytical results most likely reflect these shortcomings. In particular, the simulations predict that the larger 1.5T-CT specimen is more fracture-resistant than evidenced by the smaller 1T-CT specimen in the experiment. This discrepancy suggests that the failure strain values we used for large triaxiality are too high. Also, the simulations of the N3PB tests predict fracture initiation at much lower load point displacements than observed in the experiments, suggesting that the failure strain values we used at low triaxialities are too small. Keeping in mind these limitations, we can nevertheless draw significant qualitative conclusions from the comparison of simulations and experiments.

The simulations of geometrically similar CT specimens differing in size by a factor of 4 predict a scaling effect on the load and crack extension versus load-line deflection that is consistent with that observed experimentally for specimens differing in size by the same scale factor (but of different absolute sizes). We interpret this qualitative agreement as a demonstration that the simple fracture model of Equation (1), and the finite element implementation of the characteristic material length scale and damage evaluation, can correctly simulate the scaling effect associated with fracture initiating at sharp cracks in Mode 1 loading. It is likely that this first conclusion can be extended to other local fracture models equivalent to the model used here, as long as the characteristic length scale is also implemented in an equivalent way. We also expect that the conclusion is also valid when the model is applied to other alloys failing by ductile nucleation and quasiisotropic growth of voids.

In contrast, the prediction obtained with the local fracture model that crack initiation conditions for scaled N3PB specimens should show little or no effect of scaling is not substantiated at all by the experiments. Figure 6 provides a reason for this fundamental discrepancy. In the N3PB experiments, fracture initiation occurs by a shear localization process followed by nucleation and growth of elongated voids under mixed shear/tension loading in the zone of localized deformation. Clearly this process departs markedly from the assumed process of void growth under predominantly (triaxial) tensile stresses underlying the model of Equation (1) (and most other ductile fracture models). Therefore, there is little reason why the model should predict the experimentally observed fracture initiation behavior. According to Knott [13], the fracture initiation process by shear localization at the notch root is associated with alloys having low hardening rates, the case for HY 130 steel. For lower strength alloys with higher strain hardening rates, voids nucleate more homogeneously over the material region at the notch root. However, the initial crack still forms at an angle with respect to the specimen midplane, along lines of maximum shear deformation. Otsuka et al. [14] report that in the latter case a critical void density calculated by the Gurson yield model for porous material [15] is a good indicator of crack initiation conditions. The macroscopic mode of loading and details of the notch geometry will also affect the micromechanism of fracture initiation: notched round bars, which are used extensively to calibrate ductile local fracture models, obviously promote the mode of fracture initiation by quasi-isotropic void growth.

From these considerations, we draw the second conclusion that ductile local fracture models currently considered for fracture analyses cannot be applied to generalized geometric and loading conditions without considerable care. Although the models perform well in situations involving tensile loading of preexisting cracks, they may or may not apply to the initiation of fracture at blunt notches. Depending on the material being investigated and the loading configuration, different micromechanisms of fracture initiation can be invoked that fall outside the assumed response underlying current models.

Therefore, improved models capable of handling ductile failure by void growth under predominantly shear deformation, or completely new models, must be developed to predict ductile fracture initiation conditions and scaling laws for generalized loading and geometric configurations. We hope that this investigation will provide a motivation for other researchers to address the issues it raises. Progress along these lines holds the key to the solution of an increasingly large number of important practical problems.

\section{ACIKNOWLEDGEMENTS}

This investigation was supported by the Office of Naval Research and the Naval Surface Warfare Center, Carderock Division, under Contract N60921-93-C-0144. The authors thank Dr. G. Main and Mr. C. D. Milligan for their support. 


\section{REFERENCES}

[1] Giovanola J. H., Crocker J. E., and Kirkpatrick S. W., Eng. Fract. Mech., to be submitted, 1996.

[2] Giovanola J. H., Kirkpatrick S. W., and Crocker S. W., Int. J. Fract., to be submitted, 1996.

[3] Mackenzie A. C., Hancock J. W., and Brown D. K., Eng. Fract. Mech.9 (1977) 167-188.

[4] Mudry F., "Methodology and Applications of Local Criteria for Prediction of Ductile Tearing," Elastic-Plastic Fracture Mechanics, L. H. Larson, Ed. (ECSC, EEC, EAEC, Brussels and Luxembourg, Belgium, 1985), pp. 263-283.

[5] Hallquist, J. O. and Whirley, R. G., DYNA3D User's Manual (Nonlinear Dynamic Analysis of Structures in Three Dimensions), Lawrence Livermore National Laboratory, Report UCID-19592 Rev. 2 (1989).

[6] Beremin F. M., Met. Trans, 12 A (1981) 723-731.

[7] Norris D. M., Reaugh J. E., Moran B., and Quinones D. F., J. Eng. Mat. Tech. 100 (1978) 270-286.

[8] Bridgman P. W., "Studies in Large Flow and Fracture" (McGraw-Hill, New York, 1952).

[9] Giovanola J. H. and Kirkpatrick S. W.,"Applying a Simple Ductile Fracture Model to Fracture of Welded T-Joints," Advances in Local Fracture/Damage Models for the Analysis of Engineering Problems, AMD-Vol. 137 , J. H, Giovanola and A. J. Rosakis Eds. (American Society of Mechanical Engineers, New York, 1992), pp. 285-303.

[10] ASTM Standard E 1152-87, "Standard Test Method for Determining $J-R$ Curves," Annual Book of ASTM Standards, Section 3, Vol. 03.01 (American Society for Testing and Materials, Philadelphia, 1994).

[11] Link R. E., US Naval Academy, Annapolis, private communication (1994).

[12] Kumar V., German M. D., and Shih C. F., "An Engineering Approach for Elastic-Plastic Fracture Analysis," General Electric Company Topical Report to Electric Power Research Institute, Research Project 1237-1, Schenectady, NY, July 1981.

[13] Knott J. K., "Micromechanisms of Fracture and the Fracture Toughness of Engineering Alloys," Fracture 1977, Volume 1 (1977), pp. 61-92.

[14] Otsuka A., Tohgo K., and Okamoto Y., Nucl. Eng. and Des. 105 (1987) 121-129.

[15] Gurson A. L., J. Eng. Mater. Technol., 2 (1977) 2-15. 